\title{
CRISES, PANDEMIA E DIREITOS FUNDAMENTAIS: O PERIGO NAS INTERSEÇÕES
}

\section{CRISES, PANDEMIC AND FUNDAMENTAL RIGHTS: DANGER IN THE INTERSECTIONS}

\author{
JosÉ DOS SANTOS CARVALHO FILHO ${ }^{1}$
}

RESUMO: O objetivo das presentes considerações é o de fazer breve análise sobre os efeitos de crises profundas, como a pandemia da COVID-19, sobre o regime democrático e, especialmente, sobre a garantia dos direitos fundamentais, incluindo o de liberdade. Em tais situações, pode ocorrer a atuação restritiva do Estado, com ordens de fazer (facere) e de não fazer (non facere) às pessoas. É preciso reconhecer, porém, a tênue membrana que separa a legitimidade da ilegitimidade das medidas. Cabível, então, é o socorro ao princípio da proporcionalidade.

PAlavRAs-Chave: Democracia e crises; Restrições estatais; Supremacia do interesse coletivo; Controle da legitimidade.

ABSTRACT: The purpose of these considerations is to make a brief analysis of the effects of deep crises, such as the COVID-19 pandemic, on the democratic regime and, especially, on the guarantee of fundamental rights, including freedom. In such situations, restrictive action by the State may occur, with orders to do (facere) and not to do (non facere) to people. However, it is necessary to recognize the tenuous membrane that separates the legitimacy from the illegitimacy of the measures. Appropriate, then, is the aid to the principle of proportionality.

KEYWORDS: Democracy and crises; State restrictions; Supremacy of collective interest; Control of legitimacy.

\footnotetext{
${ }^{1}$ Professor de Direito Administrativo e Constitucional. Mestre em Direito pela UFRJ. Ex-Professor da UERJ, UFF (Pós-graduação), Univ. Cândido Mendes e cursos de preparação para concursos. Palestrante e conferencista. Procurador de Justiça do MP/RJ (aposentado). Advogado e Consultor Jurídico. Contato: josecarv@centroin.com.br.
} 


\section{INTRODUÇÃO}

Iniciada provavelmente na China no final de 2019 ou início de 2020, mas rapidamente disseminada em praticamente todo o mundo, a pandemia do novo coronavírus, cientificamente denominado de COVID-19, tem causado profundas transformações nas sociedades atingidas e evidentes alterações no modus vivendi das populações, bem como efeitos gravosos, como os altos índices de contaminação e de letalidade.

A pandemia teve natureza globalizada, difundindo-se entre quase todos os países de vários continentes. Justamente em virtude dos efeitos deletérios que marcam a doença, diversas medidas foram adotadas pelos governos como forma de enfrentamento para sua atenuação ou extinção. Algumas dessas providências, é oportuno dizer, se revelaram bastante severas e invadiram a privacidade das pessoas, compelindo-as a modificar seus hábitos e costumes e causando-lhes inegável desconforto.

Como não poderia deixar de ser, as medidas governamentais espelharam, por vezes, a imposição de restrições e condicionamentos à liberdade e a outros direitos fundamentais, quase sempre necessários ao duro enfrentamento da pandemia e, principalmente, para impedir a surpreendente velocidade de sua propagação. Sem dúvida, esse novo estado de coisas gerou inevitável perplexidade e, por que não dizer, alguns dissabores e irresignações, o que é de certo modo compreensível pela circunstância de que, na verdade, ninguém gosta de sofrer restrições.

Causaram, de fato, surpresa certas determinações governamentais que impuseram obrigações de fazer ou de não fazer, condicionaram o exercício de alguns direitos fundamentais e alcançaram as linhas da garantia constitucional da liberdade. Não sem motivo, surgiram vários questionamentos sobre a legitimidade ou não dessas medidas, pois que não estavam as pessoas preparadas para imposições de não frequentar praias, ou de não circular pelas vias públicas, ou se valer de transporte público, ou mesmo de não participar de reuniões com determinado número de integrantes.

As presentes considerações têm o escopo de proceder, objetivamente, a uma análise da legitimidade ou não dessas medidas estatais diante de situação de crises profundas na sociedade, cujos efeitos invadem diversos setores essenciais, como o empresarial, cultural, turístico, normalmente provocando gravames a pessoas e instituições. Pretende-se relembrar os parâmetros do regime democrático e confrontá-los com as restrições impostas pelo Estado para a constatação de sua alterabilidade em situações de anomalia social, invocando-se a prevalência do interesse público e dos interesses coletivos sobre interesses individuais.

Ao cabo, será realçada a extremamente tênue membrana que demarca as condutas dotadas de legitimidade e de ilegitimidade, sem prejuízo das observações sobre a dificuldade do exercício de controle sobre as atividades restritivas do governo, tendo em vista a situação heterodoxa oriunda dos períodos de crise, sempre na perspectiva do perigo que essa atuação pode causar às garantias constitucionais e à própria democracia. 


\section{REGIME DEMOCRÁTICO E PARÂMETROS ESSENCIAIS}

Foi no século XVIII que se criaram as raízes do Estado Democrático, fundado na garantia de certos valores fundamentais da pessoa humana e na exigência de organização e funcionamento direcionados à proteção desses valores. A crença nesses postulados estendeu-se pelos séculos XIX e XX, e ainda agora, no século XXI, busca-se guindá-los à condição de pressupostos essenciais da democracia. Apesar disso, os conflitos oriundos do regime têm demonstrado a extrema dificuldade "que se tem encontrado para ajustar a ideia de Estado Democrático às exigências da vida contemporânea" (DALLARI, 2011).

O fundamento principal do Estado Democrático tem assento na noção de governo do povo, mas a inter-relação entre as sociedades e o Estado a que pertencem sempre esteve envolvida em conflitos. Isso é fácil de compreender diante da realidade de que o Estado detém o poder e a força, ao passo que ao povo cabe a manifestação de vontade a que o Estado, em tese, deve submeter-se. Sem embargo desses conflitos, o regime democrático, com todos os seus equívocos, ainda se revela como o mais apropriado para respeitar a vontade popular. Por isso, celebrizou-se a concepção de Churchill, proclamada em 1947, de que "a democracia é a pior forma de governo, à exceção de todas as outras que têm sido tentadas de quando em vez".

O verdadeiro regime democrático é aquele delineado por parâmetros definidos na Constituição, mediante os quais se viabiliza a garantia da liberdade e dos demais direitos fundamentais. Pode haver Constituição sem esses parâmetros, mas ela será Constituição apenas formalmente, ou, por que não dizer, mero documento de retórica. Somente com a definição das garantias da liberdade e dos direitos fundamentais é que se poderá qualificar a carta máxima como Constituição em seu sentido material. Esta não depende necessariamente de formalização, mas dela devem sempre constar os parâmetros relativos à organização do Estado e dos Poderes e aos direitos e garantias fundamentais (ZIMMERMANN, 2006).

Os direitos fundamentais podem ser vistos em duas vertentes específicas. De um lado, numa vertente subjetiva, são aqueles que conferem aos indivíduos a pretensão no sentido de ser adotada determinada conduta, positiva ou negativa, considerando a dignidade da pessoa humana. De outro, no ângulo objetivo, os direitos fundamentais dão sustento à ordem jurídica, sendo expressamente mencionados na Constituição para conferir segurança aos indivíduos e coletividades por meio, como regra, de normas devidamente formalizadas que se sobrepõem ao próprio Estado (MORAES, 2012).

A liberdade, por sua vez, em cuja essência pode vislumbrar-se tanto um aspecto interno quanto um externo, também constitui garantia expressa no art. 37, caput, da CF. Adotando-se a perspectiva de José Afonso da Silva, a liberdade interna estampa o livre-arbítrio e a possibilidade de escolha para os titulares, ao passo que a liberdade externa é a que permite sejam superados obstáculos ou impedimentos que de algum modo hostilizem o querer individual. Com a liberdade, a pessoa 
satisfaz seu bem-estar e sua felicidade pessoal, que são, na verdade, o apanágio da democracia (SILVA, 2002).

É importante lembrar que, a despeito de serem esses direitos e garantias os parâmetros essenciais da Constituição, não são eles absolutos, mesmo em situações de normalidade social. A própria Constituição admite que, em certos casos, a lei imponha algumas restrições fundadas na necessidade de atendimento aos interesses coletivos e ao interesse público, primário ou secundário. As restrições podem surgir por intermédio de lei, editada pelo legislador com base na existência de reserva legal explícita, ou "com base em uma lei", nesse caso levadas a efeito por intérpretes do texto constitucional em sua função de perscrutar a essência dos mandamentos que compõem a linha dos direitos fundamentais (CARVALHO, 1999).

Aqui vale lembrar que, em se tratando de normas constitucionais de eficácia contida, não estão elas providas de todo o seu possível conteúdo e, com isso, nasce a permissão implícita de haver alguma redução de conteúdo efetivada pelo legislador. Usualmente, vêm com delimitações conceituais, como "ordem pública", "perigo público iminente", "bons costumes" etc. Apesar de terem aplicabilidade imediata, não se confundem com as normas cujo conteúdo se exaure dentro de suas próprias linhas (normas de eficácia plena). Por outro lado, também se distinguem das normas que, embora pendentes de regulamentação futura, não têm imediata aplicabilidade (normas de eficácia limitada), somando-se a isso o fato de que, em relação a estas, a lei futura não se limita a restringir a norma, como ocorre com as normas de eficácia contida, mas vão além, servindo como elemento de integração da norma constitucional (SILVA, 1999).

Enfim, o que se quer realçar neste tópico é o fato de que a Constituição é dotada de parâmetros essenciais ao regime democrático, mas podem eles ser alvo de restrições impostas pelo governo, ainda que em situações de normalidade, quando a norma comporta esse tipo de interpretação.

\section{PANDEMia E CRISE}

A pandemia da COVID-19 pegou o mundo de surpresa neste ano de 2020 e causou uma grande revolução nos hábitos e costumes das populações em geral. Constatado seu grande poder de contaminação, os governos foram obrigados a tomar algumas medidas que subverteram a rotina normal dos habitantes do planeta. Com o número crescente e assustador de pessoas infectadas e diante da grande quantidade de óbitos decorrentes da doença, a atuação estatal se fez ainda mais rigorosa para, ao menos, mitigar-lhe os efeitos até sua total extinção.

De acordo com as recomendações técnicas da OMS - Organização Mundial da Saúde de que essencial seria a necessidade de desagrupar as pessoas por causa da violenta força do contágio, vários países atingidos pela pandemia expediram determinações para que as pessoas não saíssem às ruas, a não ser em situações excepcionais e inevitáveis. Ou seja, foi ordenado que as pessoas permanecessem em suas casas. Retirando-as de circulação, poder-se-iam minimizar os efeitos da 
doença e, sobretudo, evitar a perigosa contaminação e o crescente número de mortos.

É induvidoso que houve discrepâncias quanto à eficácia das medidas governamentais, inclusive entre os técnicos e infectologistas, entendendo-se, por outro lado, que a pandemia não estaria a exigir esse tipo de prisão indireta, sem que as pessoas pudessem exercer seu direito de ir e vir livremente. Esse encarceramento seria incondizente com a liberdade das pessoas, ainda mais para aquelas que teriam compromissos externos a serem honrados. Era fácil entender as divergências, visto que, afinal, o vírus não era conhecido e o mundo foi surpreendido com sua chegada devastadora.

A verdade é que, mesmo com idas e vindas, a medida considerada mais eficaz para evitar a propagação da doença foi o isolamento (ou distanciamento) social, devendo as pessoas permanecer em quarentena em suas casas até que a curva da pandemia se tornasse descendente, quando então seria admitida alguma flexibilização, com a gradativa reabertura das empresas e instituições. Outras ordens estatais foram baixadas, como o uso obrigatório de máscaras nas ruas; o fechamento de estabelecimentos comerciais; a vedação a reuniões com maior número de pessoas; o impedimento ao uso do transporte público mediante aglomeração de usuários; e, enfim, várias determinações para fazer ou não fazer alguma coisa.

Com a paralisação total, praticamente, do setor produtivo - indústria, comércio e serviços - e com a assustadora perspectiva do tempo de duração da pandemia até a sua atenuação e extinção, instalou-se no país inegável situação de crise, que gerou repercussão política, social, econômica, turística - fato, aliás, também ocorrido em outros países. Quando se faz menção a situação de crise, a ideia é a de que se trata de período em que se dá o afastamento das condições normais de vida do grupo social, de modo que essa anomalia social acaba por render ensejo à intervenção mais restritiva do Estado.

É certo que essa não foi a primeira nem certamente será a última situação de crise a assolar o país, mas, como nos estamos deparando com novas realidades, se comparadas com as anteriores, cumpre que recapitulemos alguns aspectos que denotam a alteração dos parâmetros constitucionais nesses períodos esdrúxulos. Afinal, ante os questionamentos sobre a constitucionalidade ou não de certas medidas estatais, que, em plano teórico, agrediriam postulados constitucionais, parece oportuno revisitar os parâmetros de exceção contidos na Constituição em situações de crise.

\section{Alteração dos ParÂMetros CONSTitucionais}

É pacífico que a incidência das normas constitucionais não pode ocorrer de modo inflexível para todas as hipóteses da dinâmica social. A razão é de simples compreensão: a voluntas do Constituinte consiste no fato de que a Constituição deve adequar-se às relações sociais com as quais se defronta. Não teria o menor sentido que a aplicabilidade das normas constitucionais não sofresse qualquer alteração 
diante de eventual mutação social, como a que advém dos períodos de crise. Com isso, forma-se o postulado central da questão: parâmetros constitucionais voltados a situações de normalidade nem sempre se ajustam a situações anormais, como é o caso da ocorrência de crises.

Por via de consequência, toda Constituição, por mais que proclame o regime democrático e se consolide como Estado Democrático de Direito, precisa munir-se de certas válvulas de escape para enfrentar momentos de crise, nos quais sobressaia o caráter de emergência. Esses mecanismos, à primeira vista, podem parecer agressivos aos parâmetros ordinários da Constituição, mas, em sua essência, têm objetivo oposto, qual seja o de manter o equilíbrio dos Poderes e das instituições e a preservação, tanto quanto possível, dos direitos fundamentais.

São pertinentes, portanto, as observações da doutrina de que a ordem constitucional precisa contar com mecanismos "que garantam a harmonização (entre a realidade e a Constituição), o equilíbrio (entre as situações de crise e as medidas para debelá-las) e a continuidade (a não ruptura assegurada pelos limites jurídicos que caracterizam o sistema constitucional de emergência) desses elementos", vale dizer, um sistema pelo qual se possa controlar minimamente as situações excepcionais incompatíveis com a dicção constitucional ordinária (ALMEIDA FILHO, 2009).

Na mesma linha de argumentação, é preciso reconhecer que o sistema de enfrentamento de crises busca preservar a unicidade da Constituição, e isso tendo em vista seu objetivo de cuidar do ordenamento constitucional considerando a decisão constituinte, reafirmando-se, assim, o relacionamento com a comunidade política. Inatacável, desse modo, a conclusão de que "O funcionamento do Estado e a realização dos direitos fundamentais estão diretamente vinculados, nessa linha, à preservação de uma margem mínima de normalidade constitucional" (ALMEIDA FILHO, 2009). Resulta, daí, ser possível que, mesmo diante da situação de crise, possa manter-se o equilíbrio institucional, ainda que com o recurso a mecanismos de exceção.

As hipóteses de crise mais conhecidas são as que pretendem a defesa do Estado e das instituições democráticas: o estado de defesa (art. 136, CF) e o estado de sítio (arts. 137 a 139, CF). Ambos traduzem situações de anomalia constitucional decorrentes de guerras, revoluções, calamidades e outras do gênero. Examinandose o lineamento jurídico da Constituição, não é difícil constatar que nele são apontados mecanismos excepcionais visando à autopreservação do Estado de Direito, em face dos efeitos provocados pela anomalia oriunda da crise. Sem embargo de sua excepcionalidade, os instrumentos de exceção comportam-se como barreiras de contenção contra acenos de arbitrariedade ou de anarquia.

Os instrumentos de exceção espelham uma resposta jurídico-institucional para impedir que a própria Constituição seja excepcionada. Se a Constituição supera os períodos de crise social sem ser abandonada ou violada, empregando, para tanto, mecanismos mais severos e de caráter excepcional, "essa é a prova de sua estabilidade: ela consegue, tem força normativa suficiente para regular não apenas 
a normalidade, mas também as exceções", como acentua, com inteira razão, estudioso do tema (ROTHEMBURG, 2013). Na verdade, aduzimos, trata-se da Constituição normal atuando ao lado da Constituição excepcional.

Diante das crises, os mecanismos constitucionais de exceção normalmente afetam, sem dúvida, a liberdade e direitos fundamentais. É comum, por isso mesmo, que o governo lhes imponha restrições e condicionamentos para o fim de enfrentar e superar a situação de anomalia, trazendo benefícios para a coletividade, ainda mais quando se sabe que os efeitos de crises se irradiam diretamente sobre as pessoas e comumente lhes causam desconfortos e desalentos.

No estado de defesa, instituído "para preservar ou prontamente restabelecer, em locais restritos e determinados, a ordem pública ou a paz social ameaçadas por grave e iminente instabilidade institucional ou atingidas por calamidade de grandes proporções na natureza" (art. 136, caput, CF), são previstas restrições aos direitos de reunião, sigilo de correspondência e sigilo de comunicação telegráfica e telefônica, além da possibilidade de ocupação e uso temporário de bens e serviços públicos nos casos de calamidade pública (art. 136, § $1^{\circ}$, I e II, CF).

Já no estado de sítio, implantado em situações de “comoção grave de repercussão nacional ou ocorrência de fatos que comprovem a ineficácia de medida tomada durante o estado de defesa" ou de "declaração de estado de guerra ou resposta a agressão armada estrangeira" (art. 137, I e II, CF), outras são as restrições: obrigação de permanência em localidade determinada; detenção em edifício não destinado a acusados ou condenados por crimes comuns; restrições relativas à inviolabilidade de correspondência ou ao sigilo de informações; suspensão da liberdade de reunião; busca e apreensão em domicílio; intervenção em empresas de serviços públicos; e requisição de bens (art. 139, I a VII, CF).

Como se pode inferir, as medidas contempladas na Constituição para as situações de crise geradoras do estado de defesa ou do estado de sítio retratam induvidosa alteração dos parâmetros constitucionais adotados para períodos de normalidade. Constituem, na verdade, medidas de restrição à liberdade e a alguns direitos fundamentais, mas se justificam em função de seu objetivo de preservar o equilíbrio do Estado e de suas instituições. Seu fundamento tem assento no que já se denominou de anomia transitória, "sob cuja vigência, de maior ou menor duração - a depender das circunstâncias -, são afastadas ou suprimidas as restrições que, em situação normal, as leis impõem às autoridades e aos detentores do poder em geral" (COELHO, 2009).

A pandemia da COVID-19 caracteriza-se como um fenômeno sanitário mundial, que, independentemente do fator que lhe deu causa, afeta toda a estrutura do Estado e acarreta nítidos gravames às coletividades, seja pela infecção em si, seja pelas mortes que dela se originam. Pela sua fisionomia, a doença, nas condições com que vem devastando os diversos setores da sociedade, bem poderia enquadrar-se dentre as "calamidades de grandes proporções na natureza", a que se refere o art. 136, CF, para sustentação ao estado de defesa. De qualquer modo, o 
governo federal editou o Decreto Legislativo $n^{0}$ 6, de 20.3.2020, no qual ficou declarado estado de calamidade pública para justificar exceções de natureza fiscal.

A Lei $\mathrm{n}^{\mathrm{o}}$ 13.979, de 6.2.2020, relaciona várias medidas administrativas para enfrentamento do novo coronavírus, entre elas o isolamento (separação de pessoas) e a quarentena (restrição de atividades ou separação de pessoas suspeitas de contaminação de outras sem doença, e de bagagens, animais etc., também passíveis de contaminação). Além disso, prevê a determinação para a realização compulsória de exames médicos, testes laboratoriais, coleta de amostras clínicas, vacinação e tratamentos médicos específicos (art. $3^{\circ}$ ).

Essas medidas, em tese, se contrapõem à liberdade das pessoas e a alguns de seus direitos fundamentais, como o de reunião, de lazer, e, enfim, da liberdade para fazer tudo o que a lei não proíba. Em situações de normalidade, semelhantes determinações seriam à evidência inconstitucionais por refugirem aos parâmetros fixados na Carta. Mas, em se tratando de situação de crise, que afeta a estrutura do Estado, a ordem democrática e o bem-estar da coletividade, são revestidas de legitimidade, porque - não custa insistir - nos períodos de crise se alteram os parâmetros constitucionais incidentes sobre situação de normalidade.

\section{LIMITES MATERIAIS E TEMPORAIS}

A alteração dos parâmetros constitucionais tem como fundamento a ocorrência de situação de crise e de emergências, não incidindo, assim, conforme foi visto, sobre águas plácidas dos períodos de normalidade política, social e econômica. Afinal, os parâmetros alteradores configuram-se como exceções ao sistema definido na Constituição, muito embora, por mais paradoxal que pareça, tenha como alvo a preservação do equilíbrio social e do regime democrático.

Não obstante, as normas de exceção que alteram os parâmetros normais da Constituição têm necessariamente que sujeitar-se a limites, visto que, se assim não fosse, seriam fácil instrumento de abuso de poder e de arbitrariedade por parte de agentes e órgãos de governo. Equivaleria, guardadas as proporções, a um cheque em branco para atuação fora do contexto ordinário do quadro constitucional. Consequentemente, seria inócua a proteção à liberdade e aos direitos fundamentais, cujos mandamentos seriam caracterizados como mera peça de ficção. Isso seria, obviamente, incompatível com o Estado Democrático de Direito.

Quanto aos requisitos das restrições, podemos socorrer-nos da classificação de Canotilho, segundo a qual as leis restritivas de direitos devem submeter-se a requisitos formais e materiais: formais, para exigir-se que a lei obedeça ao procedimento previsto na Constituição; materiais, para que seu conteúdo se ampare nos permissivos constitucionais pertinentes, ou seja, a substância das leis deve situar-se nos parâmetros de exceção traçados na Carta (CANOTILHO, 1998). Assim como se impõe a presença de tais requisitos, o mesmo se exigirá relativamente aos limites das restrições. 
Nos períodos de crise, a aplicação dos parâmetros extraordinários tem como limite material a necessidade de expedição de medidas mais gravosas para tentar atenuar ou fazer cessar a situação de anomalia social. A legitimidade desses parâmetros, que normalmente contrariam os parâmetros adotados para situações de normalidade, pressupõe que se destinem única e exclusivamente ao combate contra a situação de crise. Como é fácil verificar, há uma grande responsabilidade por parte das autoridades incumbidas dessas medidas, porquanto, uma vez dissonantes das razões que as fundamentaram, passam a configurar-se como abuso de poder.

A necessidade interage com os pressupostos que geram a situação de crise. No estado de defesa, por exemplo, os pressupostos são a grave e iminente instabilidade institucional ou a ocorrência de calamidades de grandes proporções na natureza (art. 136, caput, CF) - a primeira ameaçando e a segunda atingindo a ordem pública ou a paz social. Ante semelhantes pressupostos, os atos restritivos à liberdade ou aos direitos fundamentais, como, por exemplo, a restrição ao direito de reunião, são balizados por sua inafastável pertinência às situações de crise definidas na Constituição. Por conseguinte, a necessidade das restrições se entrelaça com os aludidos pressupostos constitucionais - estes, o limite material para a legitimidade daquelas.

Noutro giro, qualquer ato restritivo que não guarde pertinência com os pressupostos da situação de crise não se revestirá do caráter de necessidade, afastando-se do cunho de legitimidade para constituir conduta abusiva. Significa que, fora dos limites materiais, atos de exceção encerram abuso de poder e refogem ao permissivo constitucional de admitir exceções específicas para aquela situação anômala. Pode-se afirmar, sem medo de errar, que os limites materiais das restrições dependem de sua relação de congruência com os pressupostos fixados para a situação de crise.

Os limites temporais, a seu turno, espelham a transitoriedade das medidas restritivas em função da mesma transitoriedade que envolve os períodos de crise. Nenhuma situação de crise é permanente. Ao contrário, sempre tem caráter excepcional, sendo que essa é a razão da excepcionalidade das medidas restritivas. Já se afirmou com razão: "As medidas adotáveis, como frisado, têm natureza excepcional. Assim sendo, devem ser temporárias, só utilizadas quando realmente necessárias, e, por fim, proporcionais à situação de crise que pretendem superar" (ARAUJO; NUNES JÚNIOR, 2012).

No que concerne aos limites materiais e temporais, invoca-se um dado que merece comentário. Os limites materiais das medidas restritivas são sempre expressos, e isso porque, como visto, guardam paralelismo com os pressupostos da situação de crise, os quais, da mesma forma, também têm expressividade na Constituição. Desse modo, são revestidos de maior objetividade em virtude de serem os pressupostos notoriamente declarados na disciplina constitucional. 
Contrariamente, os limites temporais das medidas restritivas nem sempre são definidos. Não há dúvida de que as medidas restritivas são sempre temporárias e provisórias. Mas o período dentro do qual podem ser adotadas pode ou não vir expresso na Constituição. Para exemplificar, o tempo de duração do estado de defesa não pode ser superior a trinta dias, admitida uma única prorrogação, por igual período, se ainda presentes os motivos que inspiraram a decretação (art. 136, $\S 2$,,$C F)$. Já no caso de guerra ou agressão armada estrangeira, o estado de sítio pode ser decretado por todo o tempo em que perdurarem tais situações de crise (art. 138, § 1ํ, CF). Infere-se, pois, que os limites temporais podem ser objetivos ou subjetivos, dependendo do que estiver previsto na Constituição.

Plasmando-se tais dados no âmbito da COVID-19, urge fazer breve reflexão sobre os limites materiais e temporais. Antes de mais nada, embora não se tenha decretado estado de defesa ou estado de sítio, é inegável que o estado de calamidade pública advindo da pandemia constitui situação de crise, de onde resulta, em primeiro plano, a necessidade de implantar medidas restritivas à liberdade e aos direitos fundamentais. Em tal cenário, há que se reconhecer a legitimidade de medidas desconfortáveis para as pessoas, como a proibição de circular pelas ruas, o uso obrigatório de máscaras, a sujeição obrigatória da pessoa a exames laboratoriais, o fechamento do comércio e de shoppings e outras do gênero.

Assim, limites materiais no período de crise decorrente da pandemia são aqueles que impõem que as medidas de governo sejam sempre pertinentes ao embate da sociedade contra a doença. Ausente essa congruência, a medida terá extrapolado os limites materiais que poderiam amparar a sua legitimidade.

Já os limites temporais, por inexistir previsão objetiva de prazo de vigência, terão inevitavelmente duração indefinida, vale dizer, estarão assentados em certo subjetivismo que consiste em avaliar se ainda perdura o estado de calamidade com risco para a saúde e a vida das populações. Por mais que se pretenda erigir um elemento objetivo para tais limites, o certo é que a avaliação em si do estado de calamidade pública pode sofrer uma ou outra variação, até mesmo entre os técnicos e cientistas - os quais, diga-se de passagem, também divergiram, desde o início, quanto à necessidade das medidas restritivas e aos métodos empregados para o combate ao novo coronavírus.

Em certo momento futuro - esperemos que seja em breve - o estado de calamidade desaparecerá e só então estará vedada a expedição de medidas restritivas. Nessa hipótese, a insistência em mantê-las implica ofensa aos limites materiais e temporais necessários à configuração de sua legitimidade.

\section{CONTROLE DA LEGITIMIDADE}

Partindo-se da premissa de que as medidas restritivas em tempos de crise se submetem a limites, materiais e temporais, constitui corolário lógico uma sucinta análise sobre a sua legitimidade. A sujeição a limites comporta a óbvia e preliminar 
conclusão de que ou a medida é legítima por estar contida dentro dos limites fixados para ela, ou, de outro lado, é ilegítima por havê-los ultrapassado. Como nem sempre a linha limítrofe entre a legitimidade e ilegitimidade é bem demarcada, cabe fazer uma ou outra observação sobre esse controle.

O exame do controle das medidas restritivas não é despiciendo, e isso porque são praticadas em período de exceção e crise. "É um direito de exceção e de necessidade, que leva à pré-compreensão de uma delimitação normativoconstitucional de instituições e medidas nas situações emergentes de anormalidade, consagrando um direito de necessidade constitucional" (FERREIRA, 1992). Assim como há exceção e necessidade, o controle da legitimidade - aduzimos - se revela importante para evitar que as restrições se convertam em arbítrio.

As restrições normalmente são formalizadas por lei, conforme autorização constitucional. Serão elas as restrições primárias, porquanto o consentimento provém diretamente da Constituição. No entanto, dependendo da situação de crise, poderão ser baixadas restrições por decreto regulamentar, que, nesse caso, se caracterizam como restrições subsidiárias, ou decorrentes. Por exceção, o Constituinte admitiu a expedição de decretos autônomos diretamente calcados na Constituição, podendo-se exemplificar com os decretos que instituem o estado de defesa (art. 136, § $1^{\mathrm{o}}$, CF) e o estado de sítio (arts. 137, caput, e 138, caput, CF). É verdade que o primeiro desses decretos deve ser submetido ao Congresso Nacional em 24 horas, enquanto o segundo demanda prévia autorização do mesmo Congresso. Mas o ato em si que mencionará as restrições será o decreto.

Considerando tais aspectos, tem-se que o controle pode ser de legalidade, quanto aos decretos regulamentares que instituírem medidas restritivas decorrentes, com base na lei pertinente, e de constitucionalidade, quanto às leis e decretos autônomos restritivos, neste último caso quando provierem diretamente da Constituição. Por outro lado, a constitucionalidade será aferida quanto aos aspectos formal e material. Se o ato for dissonante do que figura na Constituição relativamente a seu modus faciendi, a hipótese será a de inconstitucionalidade formal. Se o vício se relacionar com o conteúdo da lei ou do ato, haverá inconstitucionalidade material, que ocorre "quando a lei não está em consonância com a disciplina, valores e propósitos da Constituição" (MARINONI, 2015).

Qual o problema que pode ocorrer com o controle de legitimidade (legalidade ou constitucionalidade) das medidas restritivas em tempos de crise? A questão reclama alguma reflexão.

Quando se tratar de limites objetivos, como é o caso dos limites materiais e o dos limites temporais com definição constitucional (objetivos), o controle seguirá a mesma trilha de objetividade, visto que para o aplicador nada mais caberá senão proceder ao confronto entre o ato restritivo e os parâmetros constitucionais. $\mathrm{O}$ confronto é inteiramente vinculado, de modo que inviável será qualquer tipo de apreciação de caráter subjetivo para a conclusão sobre legitimidade. Assim, se a 
vigência da medida foi prevista para o prazo de 30 dias, será inconstitucional (ou ilegal) qualquer ato levado a cabo no $31^{\circ} \mathrm{dia}$. O confronto é simples e objetivo.

Não obstante, no caso de limites revestidos de certo grau de subjetividade, o controle de legitimidade das medidas restritivas nem sempre será muito fácil ou consistente, pois que ausentes estarão fatores objetivos de avaliação. Ajusta-se bem ao que foi dito o período de pandemia da COVID-19. Quanto ao limite material, embora seja certo que o fato gerador da crise seja o estado de calamidade pública decorrente da doença e que as medidas restritivas só têm legitimidade se pertinentes à situação, a verdade é que a própria avaliação da calamidade pública pode ser suscetível a hesitações quanto à sua existência ou não. Mesmo sendo de cunho técnico a caracterização, é possível a divergência, a exemplo, aliás, do que mais de uma vez ocorreu quanto às opiniões técnicas sobre o maior ou menor perigo da pandemia.

O mesmo se pode dizer quanto aos limites temporais. Uma vez inviável prever, com exatidão, se ainda persiste a situação de crise oriunda da pandemia, inviável será, da mesma forma, garantir por quanto tempo serão legítimas as medidas restritivas atinentes à doença. Em outras palavras, não será simples, em certas circunstâncias, assegurar a legitimidade ou não das medidas, o que obrigará, com certeza, à verificação em cada caso dos elementos que possam dar suporte à sua compatibilidade com o sistema normativo.

Como se trata de restrições a direitos, deve o intérprete socorrer-se do princípio da proporcionalidade, que visa exatamente conter o excesso de poder. Cabe-lhe, consequentemente, aferir (a) a adequação, em que o meio empregado deve ser amoldado ao fim, (b) a exigibilidade, para verificar se não há outro meio menos gravoso ou oneroso para alcançar a finalidade, e (c) a proporcionalidade em sentido estrito, em que as vantagens obtidas pelas restrições superam as desvantagens, como já consignamos em outra oportunidade (CARVALHO FILHO, 2020). Fora desses paradigmas, a medida será desproporcional e, por conseguinte, contaminada de abuso ilegítimo.

\section{CONCLUSÃo}

As presentes observações, tendo como pano de fundo a fase do novo coronavírus, alvitraram apenas, de modo sucinto, a análise de situações de crise e das medidas restritivas que necessariamente precisam ser instituídas para combate à pandemia. São medidas que, à primeira vista, agridem a liberdade e direitos fundamentais, mas, em sua essência, buscam preservar o interesse coletivo e o próprio Estado Democrático de Direito.

A pandemia da COVID-19 provocou situação de crise social, o que justifica e fundamenta a imposição de medidas restritivas, tendo em vista a alteração dos parâmetros constitucionais adotados para situações de normalidade. As medidas, todavia, só têm legitimidade se forem observados os limites materiais e temporais fixados na Constituição. 
O controle da legitimidade dessas medidas - constitucional ou de legalidade - é sempre admissível. Para os limites revestidos de objetividade, o controle é mais consistente. No que concerne aos limites com alguma subjetividade, o controle pode tornar-se mais flexível e variável diante do inevitável juízo de valor a ser empregado na situação de crise. Mas é certo que, fora dos limites, as medidas podem configurar-se como abuso de poder. Exigível, pois, que o intérprete aplique o princípio da proporcionalidade em cada caso.

Para terminar, é oportuno invocar as pertinentes considerações de Steven Levitsky e Daniel Ziblatt, de que, em situações de crise, os cidadãos ficam mais inclinados a tolerar medidas autoritárias quando temem por sua segurança. Aduzem que crises de segurança - e, dizemos nós, quaisquer crises sociais - "são momentos de perigo para a democracia", porquanto "líderes com carta branca para 'fazer o que quiserem' podem infligir grande dano às instituições democráticas", fato já ocorrido em alguns países (LEVITSKY; ZIBLATT, 2018).

\section{REFERÊNCIAS}

ALMEIDA FILHO, Agassiz. Comentários à Constituição Federal de 1988 (Coord. por Paulo Bonavides, Jorge Miranda e Walber de Moura Agra). Rio de Janeiro:

Gen/Forense, 2009.

ARAUJO, Luiz Alberto David; NUNES JÚNIOR, Vidal Serano. Curso de Direito Constitucional. São Paulo: Verbatim, 2012.

CANOTILHO, J. J. Gomes. Direito Constitucional e Teoria da Constituição. Coimbra, Portugal: Almedina, 1998.

CARVALHO, Luís Gustavo Grandinetti Castanho de. Direito de Informação e Liberdade de Expressão. Rio de Janeiro: Renovar, 1999.

CARVALHO FILHO, José dos Santos. Manual de Direito Administrativo. São Paulo: Gen: Atlas, 2020.

COELHO, Inocêncio Mártires; MENDES, Gilmar; BRANCO, Paulo Gustavo Gonet. Curso de Direito Constitucional. São Paulo: Saraiva: IDP, 2009.

DALLARI, Dalmo de Abreu. Elementos de Teoria Geral do Estado. São Paulo: Saraiva, 2011.

FERREIRA, Pinto. Comentários à Constituição Brasileira. São Paulo: Saraiva, 5º vol., 1992. 
LEVITSKY, Steven; ZIBLATT, Daniel. Como as democracias morrem. Rio de Janeiro: Zahar, 2018.

MARINONI, Luiz Guilherme; SARLET, Ingo Wolfgang; MITIDIERO, Daniel. Curso de Direito Constitucional. São Paulo: Saraiva, 2015.

MORAES, Guilherme Peña de. Curso de Direito Constitucional. São Paulo: Gen: Atlas, 2012.

ROTHEMBURG, Walter Claudius; CANOTILHO, J.J. Gomes et al. (coord.). Comentários à Constituição do Brasil. São Paulo: Saraiva: Almedina, 2013.

SILVA, José Afonso da. Curso de Direito Constitucional Positivo. São Paulo: Malheiros, 2002.

SILVA, José Afonso da. Aplicabilidade das Normas Constitucionais. São Paulo: Malheiros, 1999.

ZIMMERMANN, Augusto. Curso de Direito Constitucional. Rio de Janeiro: Lumen Juris, 2006. 